\title{
Jesús de Galilea desde el contexto salvadoreño Compasión, esperanza y seguimiento a la luz de la cruz
}

\author{
Jon Sobrino, \\ Centro de Reflexión Teológica, \\ San Salvador.
}

Me han pedido una reflexión sobre Jesús de Galilea desde el contexto de El Salvador ${ }^{1}$. Lo fundamental ya lo he expuesto, con mejor o peor fortuna, en dos libros: Jesucristo liberador Lectura teológica de Jesús de Nazaret (1991) y La fe en Jesucristo. Ensayo desde las víctimas (1999). En ellos he tratado de abordar la totalidad de la vida y destino de Jesús, y también su realidad última desde la fe. Ahora me concentraré sólo en algunos elementos que, siendo centrales en los evangelios, a mi modo de ver quedan especialmente esclarecidos por el contexto salvadoreño.

La tarea de elegir esos elementos fundamentales no es sencilla. Tendré en cuenta especialmente la cruz, no solo porque los evangelios son "la historia de la pasión con una larga introducción" (M. Kähler), sino porque el contexto salvadoreño es, ante todo, la realidad de "un pueblo crucificado" (Mons. Romero, I. Ellacuría). No es pura metáfora decir que aquí vivimos en "régimen de cruz", mientras que en otros lares se puede vivir en "régimen de buen vivir". Esto no devalúa la pascua en totalidad, que es lo verdaderamente central en la fe cristiana, pero sí la cristianiza. Sin embargo, no abordaré la cruz temáticamente, sino como principio de lectura, pienso que más útil que otros, de la totalidad de la vida de Jesús y de sus elementos fundamentales.

1. Un grupo de teólogos de Estados Unidos está trabajando en un proyecto sobre "The Galilean Jesus in Contextual Theologies". El presente artículo es el texto que me han pedido. Aparecerá también en la revista Theological Studies. 
De éstos me fijaré en la misericordia - que, importantemente, toma la forma de justicia- y en la esperanza - sobre todo de liberación y de vida-. Alrede dor de ambas cosas se pueden analizar muchas otras. Unas, positivas: reino de Dios, Dios del reino, Padre y misterio último, los pequeños, liberación, resurrección, fe, gracia... Otras, negativas: antirreino, opresión, ídolos de muerte, pecado, crucifixión. Todo ello sólo quedará insinuado.

Por último, el seguimiento. No lo es todo, pero es el quicio adecuado para que la vida cristiana - y la cristología - gire jesuánicamente. Es central en el texto evangélico: "sígueme' es la primera y última palabra de Jesús a Pedro", decía Bonhoeffer ${ }^{2}$. Y es central en el contexto salvadoreño. Ha abundado "una gran nube de testigos, mártires que han sido seguidores insignes". Sin hacer del seguimiento de Jesús algo central, el edificio cristiano se viene abajo. Es articuIus stantis vel cadentis vitae cristianae, también en el mundo de hoy.

En la presentación de la realidad de Galilea y de Jesús hay que hacer uso de métodos exegéticos e histórico-críticos, y nada tengo que añadir a los numerosos estudios sobre ello. Me extenderé, más bien, en la importancia del contexto: para el conocimiento del Jesús de Galilea mucho ha ayudado estar, consciente y activamente, en la realidad salvadoreña en la época de los sesenta a los ochenta. Esta consideración metodológica sea, quizás, lo más específico que podemos ofrecer.

Digamos por último que en estas reflexiones dos cosas me han influido novedosa y especialmente. Por lo que toca a la realidad del contexto, la generosidad, el amor, el martirio de muchos hombres y mujeres, con Mons. Romero a la cabeza, en un mundo de opresión y represión. Por lo que toca al pensamiento, el de I. Ellacuría.

\section{La estructura contextual de la teología. Lugar y fuentes}

Se solía pensar que la teología era universal, lo cual llevaba a dar importancia, prácticamente exclusiva, al uso de las fuentes: Escritura, tradición y magisterio. El lugar sólo se tenía en cuenta por razones pastorales. Pero las cosas no son tan simples. En un texto crucial, muchas veces citado, dice Ellacuría:

La diferencia no es estricta ni, menos aún, excluyente, porque de algún modo el lugar es fuente en cuanto que aquél hace que ésta dé de sí esto o lo otro, de modo que gracias al lugar y en virtud de él, se actualizan y se hacen realmente presentes unos determinados contenidos. Aceptada esta distinción, sería un error pensar que bastaría el contacto directo (aunque sea creyente y esté vivido en oración) con las fuentes para estar en condición de ver en ellas y sacar de ellas lo que es más adecuado para lo que ha de constituir la reflexión teológica. ${ }^{3}$

2. D. Bonhoeffer, E1 precio de la gracia, Salamanca, 1968, pp. 20-21.

3. I. Ellacuría, Conversión de la Iglesia al reino de Dios, San Salvador, 1985, p. 168. 
Esto significa que las fuentes son leídas en un contexto, el lugar, el ubi de las categorías aristotélicas, a lo que hay que hay que añadir la época, el quando. Ese contexto espacio-temporal puede hacer que el texto dé de sí una u otra cosa, y la pregunta fundamental es qué contexto es el más adecuado para leer el texto sobre Jesús de Galilea. No tengo una respuesta apodíctica, pero, en su generalidad, comparto lo que Ellacuría decía programáticamente: "el Tercer Mundo ${ }^{4}$ es el lugar del evangelio ${ }^{5 "}$. En este artículo queremos mostrar en directo cómo se ha leído el texto de los evangelios sobre Jesús en el contexto salvadoreño - símbolo de un Tercer Mundo mucho mayor-, con la convicción de que esa lectura ha hecho dar de sí cristianamente al texto, al menos en aspectos importantes, más que otras lecturas en otros contextos. Comenzamos por lo que el contexto tiene de $u b i$, lugar. Pero antes, hagamos algunas aclaraciones.

"Dar de sî" no significa añadir contenidos al texto cuantitativamente. Significa que el contexto puede ayudar a que, de hecho, se descubra el significado más primigenio y más profundo de un texto, qué significa liberación en el éxodo, qué significa pecado del mundo, utopía del reino de Dios, etc. Puede ayudar a que textos que han estado como enterrados, o mantenidos al margen, recuperen rele vancia y, a veces, aun existencia. Incluso en la teología europea progresista solía ocurrir que, por ejemplo, las bienaventuranzas y malaventuranzas de Lucas, la justicia e injusticia en los profetas, la liberación del éxodo, no eran tomadas centralmente en cuenta.

"Dar de sî' significa también que, en virtud del contexto - pues también el contexto, no sólo el texto tiene virtus, fuerza, energía -, los textos lleguen a afectar al estudioso y al lector, intelectual y existencialmente, de manera nueva, impensada y más profunda. Ha ocurrido, ciertamente, con textos sobre el reino de Dios, el Jesús de la historia, y, ciertamente, con textos sobre la cruz y el martirio leídos en el contexto salvadoreño.

Significa que los textos lleguen a generar conciencia colectiva, más generalizada, incluyendo también a campesinos, por ejemplo, más allá del conocimiento individual o grupal que sobre ellos tienen los especialistas. Así ha ocurrido, ciertamente, con textos sobre pobres y evangelización, sobre denuncia profética y en contra de la mentira, sobre la esperanza del reino, etc.

4. Tercer Mundo no es un concepto meramente geográfico, sino fundamentalmente histórico. Puede ser descrito como mundo de pobreza y de indignidad, en el que la vida y la dignidad no se dan por supuestas, y como mundo empobrecido, pues su postración tiene como causa importante, si no determinante, la opresión por parte de otros mundos. Y también como mundo que espera salvación, y que también la puede generar.

5. Con lo cual introduce la paradoja cristiana: es el lugar del anuncio de la buena noticia, en él ésta es aceptada más connaturalmente, y, como el siervo doliente, trae salvación. 
Significa por último que los textos lleven a nuevas formulaciones-síntesis, que marcan la dirección para comprender el todo y se convierten en articulus stantis vel cadentis fidei: "el pueblo crucificado es siempre el signo de los tiempos" (I. Ellacuría), "la gloria de Dios es el pobre que vive" (Monseñor Romero).

Cómo se sabe si el "más" que puede generar un contexto proporciona realmente una "mejor" comprensión del texto no tiene una respuesta apodíctica. Para saber si así es, pueden ayudar argumentos intelectuales de carácter más objetivo: los textos así re-leídos hacen que la fe tenga una mayor coherencia interna. Pero pienso que en este asunto es más decisiva la experiencia subjetiva, allá donde cada cual tiene que decirse a sí mismo la verdad última de un texto.

Formulado fenomenológicamente, pienso que en un contexto como el salvadoreño se puede verificar que el texto ha dado más de sí si, por ejemplo, ocurre una experiencia como la de los discípulos de Emaús: “„no ardía nuestro corazón?", lo que hoy se puede traducir como "con esta visión de Jesús, ¿no parece ahora todo "más" humano, "más" cercano al hombre de Nazaret?". Si se tiene la experiencia de Jesús en momentos de exultación: "han entendido los pobres y sencillos, no los arrogantes y prepotentes", lo que hoy se puede traducir como "por fin, hemos descubierto algo fundamental que estaba enterrado: la verdad está en los pobres de la historia, no en sus opresores". Si uno se encuentra con que "el Jesús re-leído nos ha ayudado a practicar un poco más de justicia, a amar con un poco más de ternura, a caminar más humildemente con Dios", palabras de Miqueas 6, 8 que expresan ultimidad sin apelación.

Lo importante es que el "dar de sí" de un texto se deje notar como cosa real, y como cosa buena, humanizadora. Y según esto, para verificar si un texto ha dado de sí no es suficiente remitirse a la ortodoxia del magisterio, lo cual es importante por otros capítulos. Se tiene que notar en la realidad. En El Salvador se ha notado.

Para ilustrar lo que hemos dicho, recordemos la relectura de un texto fundamental de la Escritura, el de la liberación de Egipto, que hace unos cuarenta años significó un punto de inflexión en la teología y en la Iglesia. "Gracias al contexto" latinoamericano y "en virtud de él", el texto de la Escritura dio de sí algo que había permanecido eficazmente enterrado: Dios escucha clamores de esclavos y decide liberarlos. Eso quedó claro en contextos como el salvadoreño, mientras que en otros el texto siguió prácticamente mudo o muy poco dicente.

En la Instrucción vaticana sobre teología de la liberación, IV. 3, de 1984, se afirma, por ejemplo, que la finalidad específica de Dios al poner en movimiento la liberación de aquellos esclavos habría consistido en la fundación de un pue blo que le diese culto y con el cual sellar una alianza en el Sinaí. J. L. Segundo criticó tal interpretación e insistió en que en las tres grandes fuentes, las más antiguas, jahvista, elohista, deuteronómica, "no existe rastro de esa supuesta 
finalidad"6. En el texto la finalidad primordial es que un pueblo oprimido tenga vida y viva en libertad como pueblo, lo que me parece la exégesis más correcta. Pero lo que ahora me interesa recalcar es el porqué de lecturas tan distintas. En lo fundamental pienso que ha sido la diferencia del contexto lo que ha hecho que un mismo texto dé de sí cosas distintas, y que en la conciencia colectiva se haya impuesto una más que otra ${ }^{7}$.

\section{El contexto: isomorfismo, irrupción de realidad y ruptura epistemológica}

Veamos ahora en cierto detalle el contexto salvadoreño. Nos fijaremos en tres cosas. La primera es que, dicho sin simplismos, existe un cierto isomorfismo entre la realidad de entonces, Galilea, y la nuestra de ahora, el Tercer Mundo. La segunda es que en los años sesenta la realidad irrumpió, y se hizo notar en profundidad. La tercera es que, en medio de la realidad salvadoreña, aunque no exclusivamente en ella, se dio una poderosa ruptura epistemológica en el funcionamiento de la inteligencia.

\subsection{Isomorfismo entre la realidad que aparece en el texto y en el contexto}

Estamos ante un texto que narra la realidad de Jesús de Galilea. Y estamos en el contexto de la realidad salvadoreña. Por lo que toca a un posible isomorfismo, se ha expresado en la realidad histórica y social, y también en la realidad de los seguidores de Jesús, los mártires especialmente.

\section{Isomorfismo de la realidad social: Galilea y EI Salvador}

En cuanto lugar en el que se leen las fuentes comprendemos El Salvador no como mera realidad espacial, un $u b i$, ni sólo como realidad cultural (aunque esto hay que tenerlo en cuenta como elemento importante de realidad, ciertamente en el vecino mundo indígena de Guatemala), sino sobre todo como un quid sustancial. Elementos esenciales de esa realidad sustancial son la pobreza, la injusticia, la opresión y represión estructurales, la muerte lenta y violenta. Y también lo son el aferrarse a la vida (humana y religiosamente) y la esperanza de liberación de

6. J. L. Segundo, Teologia de la liberación. Repuesta al cardenal Ratzinger, Madrid, 1985, p. 63. Según el autor, "tenemos que llegar a la última fuente del Pentateuco, la sacerdotal, durante el exilio, para que se pueda hablar, hasta cierto punto, de "el culto de la alianza celebrada en el Monte Sinaí" ( $c$ fr Ex 25-32 y 35-40), y "no como finalidad del éxodo" (ibíd).

7. En el Primer Mundo varios estudiosos del Antiguo Testamento ya habían encontrado en el texto lo que se re-leyó en el Tercer Mundo. Esto incluso fue facilitado por aque1lo. Pero la nueva lectura del éxodo se convirtió en interpretación más tenida en cuenta en la teología sistemática y pastoral, generó "conciencia colectiva" y se convirtió en paradigma de praxis, esperanza y fe, mucho más en el Tercer Mundo que en otros. Ello se debió al contexto. 
mayorías, que, inocente y en lo sustancial indefensamente, lenta o violentamente, han sido dadas muerte. Esto es históricamente evidente, y es decisivo tenerlo en cuenta para comprender, si no en los detalles, sí en lo sustancial, la Galilea de Jesús. La realidad de El Salvador ayuda a conocer la Galilea de Jesús. Qué sea pecado y gracia en Galilea se entiende mejor del pecado y gracia reales, no solo pensados, desde El Salvador.

\section{Isomorfismo de los portadores de salvación: Jesús y mártires salvadoreños}

Pero hay que insistir en otro isomorfismo, que casi nunca es tenido en cuenta, aunque, evidentemente, debe ser manejado con cuidado. En El Salvador - Tercer Mundo, no así, normalmente, y ciertamente no en la forma martirial, en el mundo de abundancia - muchos seres humanos viven, según un más y un menos, por supuesto, en pobreza o en austeridad, con misericordia sin condiciones, como la de Jesús, defendiendo a pobres y a víctimas producidas por dioses muy reales -económicos, militares, políticos, culturales, mediáticos, imperiales - . Y lo hacen consecuentemente, hasta el final, en fidelidad a Dios y con amor hasta la entrega de la vida. Son los mártires. Jesús no se avergüenza de llamarlos hermanos.

Estos hombres y mujeres son un lugar privilegiado para releer el texto sobre el Jesús de Galilea, para comprender mejor su vida, praxis y destino. Incluso iluminan el pro me de Jesús, tan querido para Pablo e Ignacio de Loyola, aunque haya que historizarlo desde el pro pauperibus.

Y ayudan a conocer, barruntar al menos, su relación filial con un Dios que es Padre en quien se puede confiar, y con un Padre que sigue siendo Dios ante quien hay que estar siempre disponibles. No me puedo extender ahora en este punto, aunque es importante insistir en él, pues a nuestras cristologías se les suele achacar un tratamiento deficiente de la relación Jesús-Dios, en favor de la relación Jesús-reino de Dios. Sin embargo, el contexto salvadoreño, no sé si en cantidad, pero ciertamente sí en calidad, ilumina la relación de Jesús con Dios. Baste mencionar los nombres de Monseñor Romero y Rutilio Grande. Se parecen no solo al Jesús evangelizador y profeta, sino al Jesús Hijo de Dios.

Y recordemos el isomorfismo teologal. Jesús "pasó haciendo el bien, porque Dios estaba con él", dijo Pedro en casa de Cornelio. "Con Monseñor Romero Dios pasó por El Salvador", dijo Ellacuría en la UCA, tres días después del asesinato. De nuevo, con todas las cautelas del caso, no se puede ignorar el isomorfismo fundamental del paso de Dios por la historia.

\section{Isomorfismo de opresión y represión a nivel planetario}

El lector en contextos lejanos al nuestro puede aducir, con razón, que El Salvador no es su contexto, y que por ello la cristología que de allí surge no es 
sin más universalizable. Pero las cosas no son tan simples. El contexto descrito no es lo esotérico, la excepción o la anécdota en el planeta. La verdad es exactamente la contraria. Esotérico es el mundo de abundancia, no el salvadoreño. Pedro Casaldáliga lo ha expresado recientemente:

Hay más riqueza en la Tierra, pero hay más injusticia. África ha sido llamada "el calabozo del "mundo", una "Shoá" continental. 2,500 millones de personas sobreviven en la Tierra con menos de 2 euros al día y 25,000 personas mueren diariamente de hambre, según la FAO. La desertificación amenaza la vida de 1,200 millones de personas en un centenar de países. A los emigrantes les es negada la fraternidad, el suelo bajo los pies. EE. UU. construye un muro de 1,500 kilómetros contra América Latina; y Europa, al sur de España, levanta una valla contra África. Todo lo cual, además de inicuo, es programado. ${ }^{8}$

Si se va al fondo real de nuestro mundo - lo que, evidentemente, se intenta celosamente mantener oculto-, se descubre un isomorfismo fundamental entre la Galilea de Jesûs y muchas otras galileas de nuestro mundo, mundo de pobres y víctimas. Este mundo reproduce, además, estructuralmente lo que ocurría en el Imperio romano, bajo el que estaba Galilea.

Es encubrimiento pretendido hacer desaparecer del lenguaje el término imperio, y es eufemismo interesado sustituirlo lingüísticamente por el lenguaje de globalización - lo cual, además, es engaño, pues en el lenguaje el término "globo" es cercano al de "esfera", que expresa "perfección", absolutamente inexistente en el actual globo terráqueo-. Y no hay que olvidar lo fundamental: imperium magnum latrocinium, que decía Agustín, ayer bajo Roma, hoy bajo la égida de Estados Unidos. Ese latrocinio es la base del isomorfismo. Lo hace evidente. Así como la crueldad. Cruel era la pax romana. Hoy, como dice Jean Ziegler, el mundo de abundancia es asesino: "el que hoy haya niños que mueren de hambre, pudiendo ésta ser evitada, hace que mueran asesinados".

Éste es el isomorfismo dominante, visto desde el pecado. Sub specie contrarii aparece también el isomorfismo visto desde la gracia: la esperanza de la Galilea de Jesús, los numerosos movimientos en que se expresaba, las praxis, incluso incipientemente liberacionistas, en definitiva la utopía: la vida de los pobres. Ahora baste mencionarlo.

8. Carta circular "Utopía necesaria como el pan de cada día", enero 2006.

9. Cfr. Platón, E1 banquete XIV-X 189c-192d. La esfera es un lugar geométrico en el cual todos los puntos de la superficie equidistan del centro. La equi-distancia sirve para introyectar subliminalmente que existe equidad en un mundo globalizado, lo cual es falsedad notoria. 


\section{Isomorfismo de los mártires jesuánicos a nivel planetario}

Y también es planetario el isomorfismo de los portadores de salvación. En muchos lugares ha habido movimientos de vida y liberación. Ha habido sobre todo una inmensa pléyade de mártires, en lo que ahora nos concentramos. Ciñéndonos a El Salvador y Guatemala, han sido asesinados dos conocidos obispos, Romero y Gerardi (más un tercero en El Salvador, que suele ser desconocido, Joaquín Ramos), alrededor de 30 sacerdotes y una decena de religiosas. La lista de catequistas, delegados de la palabra, trabajadores de lo que hoy llamamos ONG, grupos de solidaridad que ya habían empezado su trabajo mucho antes de que existiesen aquéllas, sin mucho aparato administrativo, prácticamente solo con la luz del evangelio y alguna ilustración que les proporcionaba la teología de la liberación, a veces con rudimentos de marxismo, con generosidad sin límites, con parresía para decir la verdad y denunciar los horrores, es interminable. Son la gloria de los pueblos y de muchas iglesias, no solo en El Salvador y Guatemala, sino en todo el Tercer Mundo. Baste mencionar un solo nombre: Christophe Munzihirwa, arzobispo de Bukavu, Congo, asesinado en 1996 por defender a centenares de miles de refugiados en Ruanda. Hoy le llaman el "Romero de África". El martirio jesuánico no es esotérico, ni es la anécdota ni la excepción.

\section{Isomorfismo desde la fe: el pueblo crucificado, siervo doliente de Jahvé}

A este isomorfismo de los mártires jesuánicos, extendido por el Tercer Mundo, hay que añadir otro, más difícil de precisar desde un punto de vista fáctico y en definitiva sólo perceptible desde una lectura creyente de los textos: es el isomorfismo - analógico - de los pobres y víctimas de hoy con el siervo doliente, que carga con el pecado del mundo, redime y salva. Así se ha visto en El Salvador. Pobres y víctimas han sido descritos como sacramento histórico del siervo sufriente, como "el pueblo crucificado", "el divino traspasado", expresiones de Monseñor Romero e Ignacio Ellacuría. Al nivel descriptivo, los cantos de Isaías y los relatos de la pasión encuentran correspondencia con lo que ocurre en nuestro mundo, y también a la inversa. La originalidad de la reflexión no consiste tanto en constatar esa correspondencia, sino en otorgar dignidad a las víctimas de hoy: en ellas hay algo sagrado. Y la originalidad máxima ha sido considerarlas como portadoras de salvación. En eso, sobre todo en eso, convergen con el siervo que quita el pecado del mundo y, escandalosamente, trae salvación.

En el mundo existen centenares de millones de pobres y oprimidos, en quienes, a falta de mejor palabra, asoma lo que he llamado "santidad primordial"10. el infatigable aferrase a la vida, unos con otros, en represiones, guerras, migraciones, como las de los Grandes Lagos, en refugios... Milagrosamente, muchas

10. Véase lo que escribí en Terremoto, terrorismo, barbarie y utopía, San Salvador, 2003, pp. 129-140. 
veces mantienen esperanza, of recen perdón y buscan reconciliación. Tienen además fuerza de convocatoria, que genera solidaridad, entendida como llevarse mutuamente, dar unos a otros y recibir unos de otros lo mejor que cada uno tiene. Los que vienen a ayudar desde el mundo de la abundancia al de la pobreza repiten, con agradecimiento, que han recibido más de lo que han dado. De ahí que, viendo ambos mundos, el de la abundancia y el de la pobreza, hayamos escrito extra pauperes nulla salus ${ }^{11}$. Dando un paso más, de los pobres proviene salvación. Son el siervo de Jahvé ${ }^{12}$.

El "siervo" y el "crucificado" ayudan a comprender a los pobres y víctimas de nuestro contexto. No creo que se pueda dar la vuelta a la reflexión sin caer en simplismos, pues las víctimas no llevan a comprender quasi mecánicamente y en totalidad la figura de Jesús. En la cotidianeidad su vida no era como la de las mayorías de los pobres y oprimidos de nuestro mundo. Pero sí pueden ayudar a entender el significado de su vida y destino. "En fe" aceptamos que Jesús es el siervo que trae salvación. Pero captando - con todas las cautelas del caso- que de las víctimas de hoy puede venir salvación, se puede entender también, un poco, que de Jesús de Nazaret y de su destino proviene salvación.

La conclusión es que El Salvador (el Congo, Haití, Bangladés), no así el mundo de abundancia (Washington, París, Madrid), ofrece un isomorfismo, mayor o menor, con la Galilea de Jesús, y con el Jesús de Galilea. El pueblo crucificado carga con el pecado del mundo y lo redime. Salva.

\subsection{La irrupción de realidad}

El isomorfismo que hemos analizado está basado, en definitiva, en la pobreza, ayer y hoy. Ha existido durante siglos, pero ni la pobreza que aparece en el texto evangélico, ni menos la del contexto salvadoreño ha sido tenida en cuenta en la cristología. Ahora, desde finales de los sesenta, la teología sí la ha tomado en serio. La conclusión es que para conocer el contexto, al $u b i$ hay que añadir el quando. En aquellos años algo ocurrió que cambió la teología. La realidad que acaece en el tiempo tiene un quando, y entonces se pudiera decir que la época mencionada fue un kairos, que en ella hubo discernimiento de los signos de los tiempos. Pero pienso que ocurrió algo más radical: lo que siempre había estado ahí, la pobreza, hizo irrupción. Y se hizo notar de manera inocultable.

Es cierto que en la vida de los creyentes y de la teología, especialmente la de raíces bíblicas, siempre ha sido importante tener en cuenta la realidad, pero la realidad puede simplemente "estar ahî" o puede "irrumpir". En la Biblia los grandes acontecimientos no "están ahî", sino que "irrumpen”. En el Antiguo

11. Véase mi libro Fuera de los pobres no hay salvación. Pequeño ensavo utópico-profético, Madrid, 2007.

12. También han buscado organizarse y luchar contra un enemigo mil veces superior. 
Testamento "irrumpieron" clamores de esclavos e "irrumpió" el Dios de los padres con su promesa de estar siempre con su pueblo y llevarlo a la vida. En el Nuevo Testamento "irrumpieron" sufrimientos de pobres, enfermos y viudas (aunque el lenguaje no sea tan vigoroso como el del éxodo), e irrumpió Jesús de Nazaret, y así se le describe en los textos. Habló con autoridad, ningún miedo le impidió decir la verdad, ni paralizó su libertad. No huyó de conflictos, peligros y amenazas de muerte. Su caminar por Galilea no fue un deambular, ni su obrar se redujo a hacer cosas buenas, sino conflictivas, ni a comunicar verdades genéricas, ni siquiera solo éticas, sino que lo más central suyo fue la profecía. Después de pasar haciendo el bien, murió en una cruz "con un gran grito". No fue la suya una muerte placentera como la de Sócrates o Séneca. Jesús, pues, en vida y en muerte, "irrumpió". Y la resurrección fue también, y sobre todo, no un acontecimiento prodigioso, sino una "irrupción" de Dios.

Esta "irrupción de realidad" es lo que configura la teología. Es cierto que también en lo cotidiano se hace presente el misterio de Dios. Pero cuando la realidad "irrumpe", la manifestación de Dios tiene una calidad especial. Sacude de muchas formas. Y fuerza a pensar, a hacer teología.

La radicalidad de la irrupción de la realidad no se puede exigir ni programar, ni tiene por qué ocurrir aun en circunstancias en sí mismas importantes. En mi opinión, en el Vaticano II, y más recientemente en Aparecida, muchas cosas fueron bien captadas, pero no creo que la realidad llegó a "irrumpir". Sí irrumpió en Medellín, de modo que, en mi percepción, no fue una simple aplicación del concilio, sino que los participantes $-\mathrm{y}$ análogamente los textos - se dejaron configurar por la realidad que "irrumpía" con fuerza, lo que explica el impacto que causó ${ }^{13}$. Y sobre esa irrupción está fundamentada también la teología de la liberación. Ésta no ha sido construida sobre, y empujada por, una tradición ya constituida, ni sobre una doctrina ya conceptualizada, aunque algo de ello - lo mejor que venía de Europa- ayudó. El fundamento y principio - lo que principió teología - fue la irrupción del pobre y de Dios en él, como bien lo intuyó Gustavo Gutiérrez ${ }^{14}$.

13. En mi opinión, también en la CG 32, promovida por el Padre Arrupe, al definir "la lucha por la fe y por la justicia" como la misión crucial de nuestro tiempo, hubo en lo fundamental una irrupción de realidad. No creo que se llegó a ella como conclusión de la reflexión, ni siquiera solo como resultado de un discernimiento. Vino de fuera, soberanamente, poderosamente. Había irrumpido la realidad de la injusticia y de la increencia idolátrica. Y también la necesidad de volver a lo esencial del cristianismo. Desde entonces 49 jesuitas han sido asesinados en el Tercer Mundo por luchar contra la injusticia. Pienso que es una prueba de que habia irrumpido la realidad y de que la realidad movía a esa lucha crucial.

14. Véase lo que escribí en "La raíz de la teo-logía de la liberación", en Cátedra Chaminade, Teologías del Tercer Mundo, PPC, Madrid, 2008, pp. 163-177. 
Algo parecido podemos decir de las cristologías que se fueron desarrollando entre nosotros. Sin duda ayudaron reflexiones venidas de fuera, de Rahner y Moltmann, de Dupont y Jeremias. Pero para la relectura de los textos fue esencial que irrumpiese una realidad que recordaba a la de la oprimida Galilea, y que irrumpiesen seres humanos que recordaban a Jesús: su compasión, su honradez con lo real, su profecía, su valentía en el conflicto, su fidelidad hasta la cruz, su oración, su confianza y disponibilidad en y ante el Padre-Dios. Ese Jesús irrumpió como el Hijo, al que tenemos que configurarnos, y como el hermano mayor a quien debemos seguir. Ambas cosas se hicieron realidad en buena medida.

La consecuencia es clara. Una teología basada en la irrupción de realidad tiene unas raíces, valga la redundancia, radicales. Y por definición también tiene problemas, pues una irrupción no ocurre todos los días, ni es fácil mantener la luz y la fuerza que produjo la irrupción original. Pero sea cual fuere la dificultad de mantenerla, hay que superar la tentación de ignorarla. Hoy en día siguen existiendo realidades, que pueden ser tan impactantes, o más, que las que irrumpieron en nuestro contexto, como nos lo dicen Casaldáliga, Ziegler, Ramonet. Medios de comunicación, gobiernos y partidos, instituciones culturales, políticas y también religiosas, se encargan, cada una a su modo, de trivializar la realidad, esconderla. Y tratan, sobre todo, de que no se convierta en "irrupción" que genera praxis y teología.

Y por lo que toca específicamente a la teología, es claro que varias cosas disuaden de mantener la irrupción en su vigor original. Sobre todo los costos: difamación, persecución, muerte en la sociedad y, de otras formas, en las iglesias. Entre nosotros ha sido evidente. Pero también es claro que si no se deja irrumpir la realidad, los textos del pasado fácilmente enmudecen y no dan de sí.

\subsection{La ruptura epistemológica}

A la irrupción de realidad en América Latina acompañó una ruptura epistemológica. Lo más novedoso fue relacionar razón teológica y praxis (histórica, eclesial, pastoral), en lo que convergían teólogos tan distintos como Gustavo Gutiérrez y Hugo Asmann. Entre nosotros, inspirado en Zubiri, Ellacuría elaboró - y amplió- una comprensión determinada de lo que significa inteligir. Se debe aplicar a toda forma de inteligir, pero de hecho la profundizó al analizar el inteligir de la teología latinoamericana en cuanto teología de la liberación ${ }^{15}$.

15. Véase su artículo programático "Hacia una fundamentación filosófica del método teológico latinoamericano", ECA 322-323 (1975) 409-425. Por mi parte, reflexioné sobre la ruptura en "El conocimiento teológico en la teología europea y latinoamericana", ECA 322-323 (1975). El contexto no solo puede hacer que un texto dé más de sí, sino que puede ayudar también a que la inteligencia funcione de una manera específica, y, en este caso, mejor. 
Su propuesta resultaba novedosa, y en cosas importantes prácticamente contraria a las epistemologías al uso. Por eso hablamos de ruptura epistemológica. Lo fundamental de esa ruptura consiste en que la inteligencia se vuelque a la realidad. Hay que "aprehender la realidad y enfrentarse con ella" ${ }^{16}$, lo cual se desdobla en tres dimensiones: "hacerse cargo de la realidad" (dimensión noética), de origen zubiriano, a lo cual Ellacuría añadió el "cargar con la realidad" (dimensión ética) y el "encargarse de la realidad" (dimensión práxica). Por mi parte, más por experiencia e intuición que por reflexión teórica, he añadido "el dejarse cargar por la realidad" (dimensión de una inteligencia agraciada).

Aplicado esto a la inteligencia teológica, el encargarse de la realidad le llevó a definirla como "el momento ideológico de la praxis eclesial"17, cuya finalidad era "la mayor realización posible del reino de Dios en la historia"18. Por mi parte traté de retomar la intuición y definí la teología como intellectus amoris (iustitiae, misericordiae) ${ }^{19}$, más allá del intellectus fidei de Agustín y del intellectus spei de Moltmann en su Teología de la esperanza.

Recalcar la dimensión práxica de la inteligencia no era, como hemos dicho, novedad total en la teología latinoamericana. Sí pienso que fue más novedosa y exigente la dimensión de "cargar con la realidad". La inteligencia "no se ha dado al hombre para evadirse de sus compromisos reales, sino para cargar sobre sí con lo que son realmente las cosas y con lo que realmente exigen" ${ }^{20}$. No se puede inteligir adecuadamente la realidad sin la disponibilidad a cargar con lo oneroso de ella - lo que no suele tomarse muy en serio-. El asesinato del pensador Ellacuría, filósofo y teólogo, puede fungir como simbolo de una inteligencia que cargó con lo real. Y tampoco es casual que la teología salvadoreña haya sido pionera en hacer de la persecución y del martirio temas centrales de la teología en sentido estricto - no solo pastoral o espiritual - , porque cargaba con una realidad que las producía.

Y hubo ruptura en el modo de "hacerse cargo de la realidad". Supone "un estar en la realidad de las cosas y no meramente un estar ante la idea de las cosas o en el sentido de ellas"21.

16. Ibid., p. 419.

17. I. Ellacuría, Estudios Eclesiásticos 207 (1978) 457-476.

18. I. Ellacuría, "Aporte de la teología de la liberación a las religiones abrahámicas en la superación del individualismo y del positivismo", Revista Latinoamericana de Teología 10 (1987) 9.

19. Véase J. Sobrino, “Teología en un mundo sufriente. La teología de la liberación como “intellectus amoris'”, Revista Latinoamericana de Teología 15 (1988) 243-266.

20. I. Ellacuría, "Hacia una fudamentación", óp. cit., p. 419.

21. Ibíd. 
Un ejercicio de la inteligencia así entendido tiene como referente la realidad concreta que hemos llamado el "contexto". Estando adecuadamente en el contexto, es decir, "en la realidad de las cosas", se releyeron los "textos" sobre Jesús, y se inteligieron práxica, ética y agraciadamente. Veámoslo.

"Encargarse de la realidad [de Jesús]" (dimensión práxica) significaba, muy centralmente, construir hoy el reino, lo que hacía comprender mejor, como por cierta afinidad, lo que significaba el reino anunciado por Jesús, reino de vida, justicia, misericordia, esperanza, y las actividades de Jesús a su servicio, anuncio, misericordia, profecía... Y ciertamente significaba conocer mejor lo que era el antirreino, pues al operar sobre la realidad para cambiarla se experimentaba la realidad de una fuerza negativa y destructora, poderosa y contraria, lo cual a su vez, sub specie contrarii llevaba a conocer el reino. Y ese mejor conocimiento del reino y del antirreino, al encargarnos hoy del reino, ayuda también a "hacerse cargo" de la persona de Jesús, pues el reino no era una realidad entre otras, ni siquiera la más importante, sino aquella con la que él vivía en relación constitutiva.

"Cargar con la realidad" (dimensión ética) significaba cargar con lo que cargó Jesús: persecuciones, difamaciones, torturas, de parte del poder económico, militar, cultural, religioso... De nuevo, por cierta afinidad, ello facilitaba "hacerse cargo" de la cruz de Jesús y de sus causas, y del Jesús crucificado y de sus victimarios. "Cargar con la realidad" llevaba a hacerse cargo del crucificado Jesús.

"Dejarse cargar por la realidad" (dimensión de una inteligencia agraciada) significaba aceptar agradecidamente una fuerza y una luz, semejantes a las que "cargaron con Jesús". No es fácil - desde los textos - saber qué es lo que históricamente - otra cosa es su experiencia del Padre - "cargó con Jesús". Pero al menos eso lleva a preguntarse si también Jesús experimentó gracia, y en qué pudo consistir ésta, pregunta que no suele ser habitual en la cristología.

En un contexto distinto K. Rahner escribió unas lúcidas palabras que pueden iluminar la dialéctica de "cargar y ser cargado". En uno de sus últimos textos escribe que "el cristianismo es una pesada carga ligera. Cuando uno carga con ella, ella carga con uno, y cuanto más tiempo viva uno, tanto más pesada y más ligera llegará a ser"22. Pienso que algo parecido ha ocurrido en El Salvador. Dicho en general, ha habido que cargar con la realidad, pero ella ha cargado con uno. Monseñor Romero tuvo que cargar con la represión al pueblo, pero dijo que "con este pueblo no cuesta ser buen pastor". En nuestro contexto, para "hacerse cargo" de Jesús, hay que "cargar con él". Pero "Jesús carga con uno".

La conclusión es que para inteligir quién es Jesús no basta con "estar entre conceptos", sino que hay que "estar entre realidades" hoy en forma análoga

22. K. Rahner y K. H. Weger, ¿Qué debemos creer todavia? Propuestas para una nueva generación, Santander, 1980, p. 190. 
como él estuvo entre las realidades de entonces. Ni siquiera basta, por buena y deseable que sea, la kniende Theologie. Hay que pasar por la ruptura epistemológica, volcarse a lo real, encargarse de ello, cargando con ello y dejándonos cargar por ello. De otra forma los textos dan menos de sí.

A veces han dado de sí lo contrario de lo que pensamos ser su mensaje originario. Sin ánimo de exagerar, no deja de ser paradójico que, por una parte, la realidad de Jesús de Galilea ha sido bien investigada de modo que se ha llegado a resultados teóricos importantes. Pero, por otra, esa realidad a la que se ha llegado no ha tenido en el lector, y en la conciencia colectiva, un efecto todo lo vigoroso que pudiera y debiera ser. $\mathrm{Y}$ es que los conceptos tienen no solo "contenido", sino también "peso".

Sin irrupción de realidad y sin ruptura en el modo de inteligir, el concepto puede ser correcto, pero liviano en exceso. Entonces, la realidad tras el concepto puede permanecer excesivamente ajena al sujeto de la teología, y a la conciencia colectiva, y con mayor dificultad puede desencadenar un proceso de pensamiento vivo y creativo. Con irrupción de realidad y ruptura epistemológica, el concepto tiene peso, puede ayudar a transformar al sujeto pensante, exigírselo, ponerlo en esa dirección al menos. Puede llegar a formar parte de la conciencia colectiva, y desencadenar un proceso más vivo y creativo.

Eso es, pienso, lo que ha ocurrido en el Tercer Mundo con los conceptos de liberación y del Jesû́s histórico. Podrán ser limitados y son siempre mejorables, por supuesto, pero tienen un pondus ${ }^{23}$ especial. Cuando se está en medio de la realidad, y cuando la inteligencia se encarga de la causa de Jesús, carga con ella y se deja cargar por ella, el concepto no solo podrá ser preciso y científico, sino vigoroso. Tiene pondus. $\mathrm{Y}$ eso se suele transmitir, con limitaciones ciertamente, al hablar de Jesús.

Una última reflexión sobre el contexto. Hemos hablado sobre su importancia para que un texto dé más y mejor de sí. Pero también hay que tener presente lo que X. Alegre, estudioso del Nuevo Testamento, repite con frecuencia: "un texto fuera de un contexto no es más que un pretexto". Se refiere al contexto en que se escribieron los textos bíblicos, pero su advertencia también se puede aplicar al contexto en que se leen hoy. Sin tener centralmente en cuenta el contexto de

23. Una verificación del pondus que tiene el concepto liberación, en la teología que lleva ese nombre, es su difusión en muchos lugares, y también la naturalidad con que se ha ido ampliando el contenido: liberación de opresión, de raza, etnia, género, religión - análogamente-, hasta de la que sufre la madre tierra. Cristianos y teólogos han captado en "liberación" un concepto de enorme profundidad y utilidad para poner en palabra opresiones enterradas y fomentar esperanzas de liberación. No ha habido marketing ajeno al concepto, sino un concepto con pondus. Haberlo presentado así es el mérito permanente de la obra pionera de Gustavo Gutiérrez. 
realidad actual, un texto - todo lo eximio que se quiera, los del evangelio de Juan, por ejemplo - puede quedar reducido a configurar la experiencia personal del creyente (cosa muy importante), puede quedarse en ser información acerca de realidades del pasado o remitir a realidades vaporosas. Y cuando eso ocurre, el texto se puede convertir en pretexto, excusa, para no tener que enfrentarnos hoy con Jesús ni encargarnos de lo que su realidad nos exige y posibilita en el presente, ni cargar con sus exigencias.

\section{Elementos fundamentales del Jesús de Galilea}

\subsection{La cruz de Jesús: luz que ilumina la totalidad}

La vida de Jesús está hecha de muchas $\operatorname{cosas}^{24}$. El contexto puede iluminar su totalidad, pero según sea el contexto iluminará más específicamente unas u otras. Desde el contexto salvadoreño analizaremos brevemente tres: la misericordia de Jesús, la esperanza que suscita y el seguimiento que exige - y en relación con ellas, se pudieran analizar muchas otras - . Diré unas breves palabras sobre cada una de ellas, pero lo haré a partir de la luz específica que proviene de la cruz.

Dar prioridad a la cruz no es arbitrario. Ya dijimos al principio que la cruz es central en el texto de los evangelios. Y por lo que toca al contexto salvadoreño, también dijimos que vivimos "en régimen de cruz", mientras en otros lugares se puede vivir "en régimen de buen vivir". La cruz también ha sido central en la teología, la de Pablo, Marcos y Juan, la de Lutero, la de Bonhoeffer y Moltmann. En la actualidad, no creo que sea ése el caso, aunque sí lo es en los más lúcidos. En el tratamiento del pluralismo religioso, J. I. González Faus insiste en '“el exclusivismo del crucificado' como [lo] irrenunciable cristiano" 25 . Es lo no negociable. Incluso la resurrección de Jesús y la esperanza de los cristianos - sin las que no hay cristianismo - se entienden mejor desde la cruz de Jesús y desde el amor de los mártires que a la inversa.

\subsection{La misericordia}

a) En Jesûs y en el contexto salvadoreño. La "misericordia" - otros, como Metz, prefieren usar el término "compasión"- es central en Jesús. Para conseguir su favor los pobres y enfermos no tenían más que decir: "Señor, ten misericordia de mî'. Por su parte, Jesús habla y, a su modo, teoriza sobre ella, sobre todo en la parábola del buen samaritano (Lc 10, 29-37). Al hacerlo se describe a sí mismo.

La misericordia, también en Jesús, no es solo un sentimiento, sino una acción; más exactamente una re-acción en contra de lo que han hecho opresores

24. Como lo muestra el reciente libro de J. A. Pagola, Jesús. Aproximación histórica, Madrid, 2007.

25. J. I. González Faus, E1 rostro humano de Dios, Santander, 2007, p. 203. 
y victimarios. No consiste en cumplir un mandamiento, aunque Jesús cuenta la parábola del buen samaritano para mostrar en qué consiste el gran mandamiento: el amor al prójimo. No pertenece al ámbito de lo religioso (aunque se pueda y deba hacer presente en él), pues ni Dios ni la sinagoga - las iglesias, diríamos hoy - aparecen como esenciales para exigir su cumplimiento. Y tampoco aparece que en el ámbito de lo religioso exista una especial predisposición a su ejercicio, pues no reaccionan con misericordia sacerdotes y levitas, sino, al contrario. Reacciona alguien no bien situado en lo religioso, un samaritano.

Esto significa que para Jesús la misericordia remite a ultimidad. No se puede ir más allá de ella. La víctima tendida en el camino toca la fibra más honda de lo humano, splachnon, entrañas, corazón. Y la misericordia devuelve a las víctimas lo último: vida. Y también dignidad. Lo primero es evidente, pero es importante recalcar lo segundo. Cuando Jesús actúa con misericordia, los seres humanos en necesidad no solo reciben ayuda, sino que recuperan dignidad. A los sanados les dice: "tu fe te ha curado", es decir "tú te has curado". Y a la mujer pecadora le dice: "tu fe te ha salvado". Los seres humanos dejan de estar divididos en dos: misericordiosos benefactores unos y receptores de ayuda otros. Todos son humanos.

El contexto salvadoreño esclarece la ultimidad de la misericordia. Cuando preguntaron a Monseñor Romero qué hacer ante el sufrimiento de la gente, les dijo: "que no se olvide que somos hombres, y que aquí están, muriendo, huyendo, refugiándose en las montañas". Sugirió ayudas concretas, pero terminó con algo más fundamental que remite a ultimidad: "que no se olvide que somos hombres". De esa forma, el misericordioso recupera su propia ultimidad.

Y también como Jesús, en el ejercicio de la misericordia devolvía dignidad. Maestro del pueblo, les decía: "Ustedes son mi profeta". Abogado del pueblo, arriesgando todo por ellos, les decía: "Con este pueblo no cuesta ser buen pastor". El pueblo recuperaba su dignidad negada.

Según el contexto, la misericordia adopta formas concreta, y es importante tener en cuenta. Distinta fue la del Padre Kolbe, sustituyendo a un condenado a muerte en un campo de concentración, y la de la madre Teresa, desviviéndose por los más abandonados. En El Salvador la misericordia ha tomado diversas formas: asistir a los que huyen, ayudar a la organización popular, defender derechos humanos, hasta enterrar a los muertos, que decía Monseñor Romero. Y también fue misericordia insigne trabajar por una negociación que pusiese fin a una guerra cruel, como lo hizo Ignacio Ellacuría, en lo cual, por cierto, le fue la vida.

En el contexto salvadoreño el horizonte de la misericordia ha sido la liberación y el instrumento fundamental la justicia. Conceptualmente se pueden distinguir misericordia y justicia, pero real y existencialmente están mutuamente relacionadas. La misericordia-justicia es, esencialmente, dialéctica y por ello conflictiva: es defender a unos en contra de quienes los victimizan. Lleva a la lucha contra el opresor. 
b) La luz de la cruz. La cruz de Jesús especifica su misericordia. Entró en conflicto por ser dialécticamente misericordioso, luchando contra la injusticia. Y fue consecuentemente misericordioso, pues se mantuvo en esa lucha hasta el final, hasta la cruz.

También lo ilumina la realidad salvadoreña. Con ocasión del asesinato de uno de los seis sacerdotes que le precedieron, Monseñor Romero dijo lapidariamente: "se mata a quien estorba". El estorbo consistía en desenmascarar y denunciar a opresores, pero no para sacar provecho propio ni por defender a la Iglesia, ni siquiera para hacer avanzar una causa-en-sí (libertad, justicia, democracia). El estorbo provenía de querer "defender a pobres indefensos, amenazados, oprimidos, torturados, desaparecidos, asesinados". La cruz es, entonces, claramente consecuencia de una misericordia específica: la que surge de defender a víctimas en contra de sus victimarios. Desde esta misericordia, que no es solo ayuda, sino que defiende a víctimas, hay que comprender el fenómeno nuevo y masivo de los mártires ${ }^{26}$.

"Martirio" es un concepto histórico, y se puede discutir cuál es el analogatum princeps y cuál el más relevante en la actualidad. En el contexto salvadoreño, mártir es quien da la vida por la defensa del pobre, es decir, por causa de la justicia - y a través de ello los creyentes dan testimonio del Cristo que es Jesús-. Los mártires son, entonces, los misericordiosos insignes, que aman y defienden a las víctimas, transforman ese amor en lucha por la justicia, y por ello son asesinados. Son los consecuentemente misericordiosos. Se parecen a Jesús y mueren como Jesús. Los llamamos mártires jesuánicos.

Esta misericordia-justicia, iluminada por acabar en cruz, ilumina también, más allá incluso de las bellas palabras de los salmos, qué significa que Dios es un Dios de misericordia. Al hablar de la opción por los pobres, Puebla hace esta solemne afirmación teologal, con dos precisiones esenciales. Una es que la opción de Dios por los pobres es gratuita: "cualquiera que sea la situación moral en que se encuentren". Y la otra es que es defensora en contra de opresores: "Dios toma su defensa y los ama" (n. 1142). El amor de Dios es misericordia activa, pero es además misericordia arriesgada, pues defiende a los pobres de sus victimarios. Ese riesgo - misterioso, escandaloso-, que asume el mismo Dios, es lo que aparece historizadamente en la cruz del Hijo.

26. Es sabido, pero es bueno recordarlo para ilustrar el "plus" de significado que el martirio otorga a la misericordia, que Monseñor Romero y la madre Teresa fueron insignemente misericordiosos - y ambos nominados el mismo año, 1979, al Nobel de la paz-. Monseñor Romero murió mártir. La madre Teresa no. E1 proceso de beatificación de Monseñor está estancado porque su misericordia fue conflictiva $-\mathrm{y}$ su recuerdo sigue siéndolo-. La madre Teresa ya ha sido beatificada. 


\subsection{La esperanza}

a) En el evangelio y en el contexto salvadoreño. En el texto de los evangelios la esperanza es central. Programáticamente dice Jesús: "el reino de Dios se acerca". Y Boff comenta: "Jesús articula un dato radical de la existencia humana, su principio esperanza y su dimensión utópica. Y promete que ya no será utopía, objeto de ansiosa expectación ( $c f$ L Lc 3, 14), sino topía, objeto de alegría para todo el pueblo ( $c f r$. Lc 2, 9)"'27. En su tiempo el reino de Dios expresaba históri camente la esperanza de un pueblo en grandes dificultades materiales, sumido en una crisis de identidad cultural y política. Por eso Jesús suscitó un indudable eco popular.

Y también se puede uno preguntar por la esperanza del propio Jesús. En la cena de despedida mantiene la esperanza de volver a "beber del fruto de la vida en el reino". Varias palabras suyas, al observar a los pobres y sencillos, pienso que pueden ser interpretadas como experiencias de confianza y gozo, y creo que también de esperanza. Su asombro ante la generosidad de la viuda en el templo y ante la audacia de la hemorroísa; su júbilo porque los pequeños entienden, y no los grandes y sabios, le debieron causar esperanza. Y ciertamente su esperanza está presente en su confianza en el abba.

Experiencias como éstas son también reales en El Salvador, y pienso que contextos como el salvadoreño han abierto los ojos para captar la esperanza de los pobres y la del mismo Jesús. Desde la esperanza de liberación histórica, con dificultades, fracasos y desengaños, se ha revalorizado la buena noticia de que el reino de Dios "se acerca".

b) La luz de la cruz. Y también irrumpe la paradoja cristiana. La esperanza en El Salvador y en el Nuevo Testamento está íntimamente relacionada con la cruz. Lo está de dos formas. En primer lugar, la resurrección de Jesús es un símbolo de esperanza cualificada, por causa de la cruz. Pedro lo formula con precisión en cinco discursos de los Hechos: "Ustedes lo mataron, pero Dios lo resucitó". La acción resucitante de Dios no es, entonces, simplemente omnipo tencia ante un cadáver, lo que generaría una expectativa de "más vida", sino que es justicia ante una víctima inocente, lo que genera una esperanza específica: "que el verdugo no triunfe sobre la víctima", tan citado por Horckheimer. En este sentido, sobre todo, en El Salvador la resurrección es símbolo de esperanza.

Pero hay algo todavía más audaz: también la cruz en sí misma ha sido fuente de esperanza. No es inconsciencia o insensatez. En la Escritura, el siervo doliente y el Cristo en cruz, en El Salvador los innumerables mártires salvadoreños generan en sí mismos esperanza. El hecho es claro, por difícil que resulte comprenderlo y aceptarlo en otros lugares. Lo decisivo es saber y explicar por

27. L. Boff, “Salvación en Jesucristo y proceso de liberación”, Concilium 96 (1974) 378. 
qué. Moltmann lo ha dicho con estas palabras: "No toda vida es ocasión de esperanza, pero sí lo es la vida de Jesús que, por amor, tomó sobre sí la cruz". En nuestro contexto esto es verdad. Más allá de cálculos, optimismos, expectativas, allí donde hay amor, allí surge esperanza. El amor es lo que mueve a creer y esperar, misteriosamente, que el bien tiene más entidad, más poder que el mal. Ante el amor, se puede seguir viviendo. La cruz, la que es cruz por amor, genera también esperanza.

Hemos recordado a los mártires en el contexto de la misericordia: son los consecuentemente misericordiosos. Ahora los recordamos en el contexto de la esperanza: han dado su vida por amor, y son generadores de esperanza. El hecho no se puede negar. Ocurre con Monseñor Romero y con miles de mártires. Se les recuerda y se les da gracias. Los aniversarios, con lágrimas, son momentos de gozo, de recordar un gran amor. Mantiene la esperanza.

\subsection{Seguimiento y pascua}

En el evangelio Jesús llama al seguimiento, a reproducir su vida, práxica y evangelizadora. Como él, hay que pasar "haciendo el bien". Y lo mismo exige a sus discípulos. Por lo que toca a El Salador, no hace falta mencionar la nube de testigos, muchos de ellos y ellas mártires, en la historia reciente salvadoreña: han pasado haciendo el bien.

Y Jesús añade, con clarividencia, que en la historia eso significa introducirse en lo conflictivo y cargar con lo oneroso: "si alguno quiere venir en pos de mí, niéguese a sí mismo, tome su cruz y sígame". Lo acabamos de ver en los mártires. Pero, además, responder a la llamada al seguimiento es la forma jesuánica de cumplir lo que Dios pide en Miqueas 6, 8: "practicar la justicia y amar con ternura, caminando humildemente con Dios". En ambos casos se trata de caminar.

El seguimiento nos confronta con el caminar de Jesús, y la cruz le otorga absoluta ultimidad. Así aparece en el texto del evangelio y en el contexto salvadoreño. En lo que ahora queremos insistir para terminar estas reflexiones sobre Jesús y Galilea es que el seguimiento nos configura según Jesús, nos hace afines, según un más y un menos, a la realidad de Jesús. Y eso tiene consecuencias decisivas: en el seguimiento podemos dar un paso a la fe por afinidad - y según esa lógica, también el seguimiento pudiera ser el lugar de abandonar la fe-.

En el seguimiento, más que fuera de él, pueden surgir con mayor agudeza las preguntas de la fe: si, siendo como Jesús, captamos que todo tiene sentido o que todo es absurdo, si la esperanza es sensata o si es más sensata la desesperanza, la resignación o el carpe diem. Y a ello le puede acompañar la pregunta de la teo-dicea: ¿por qué si el hijo de Dios, y Dios en él, ha pasado por este mundo, el mundo sigue produciendo mal y no bien? ¿Por qué no cambia el mundo y no actúa Dios? ¿No tendrían razón Marcos y Mateo al hacer expirar a Jesús, represen- 
tándonos a todos, con el grito desgarrador: "Dios mío, Dios mío, por qué me has desamparado"? A esta pregunta sin respuesta solo se puede añadir, balbuciendo, que Dios es misterio irrecuperable, silente e inactivo ante el mal. Pero por ella hay que pasar. Se pasa con mayor agudeza, pienso, dentro del seguimiento y no en la mera contemplación.

Pero en el seguimiento puede aparecer también el sentido y el gozo. El ser como Jesús hace que la propia vida tenga sentido, y se vea, o se vislumbre, que "entre nosotros ha aparecido la benignidad de Dios". Esta bondad, con muchos altibajos, sigue empujando la historia hacia el bien, hacia lo nuevo y hacia adelante. Siguiendo a Jesús, el hermano mayor y el Hijo primogénito, y junto con Dios, el Padre de Jesús, se puede seguir caminando "hasta que Dios sea todo en todos". Para muchos esto ha significado redescubrir una buena noticia.

Pasar así por la historia es anticipo de la pascua: pasamos por la muerte y pasamos por la vida. Aunque solo al final se resuelve la dialéctica. En el presente estamos salvados in spe. Pero la realidad del presente aparece como sacramento, modesto, de la pascua definitiva.

Quizás lo más extraordinario del contexto de El Salvador, y de lugares semejantes, es que hay creyentes que siguen a Jesús y siguen caminando humildemente con Dios. Son gente de fe y de entrega. Y en la fe de esos mártires muchos otros son llevados en su propia fe.

Para mí no hay duda de que estos mártires son la realidad más crucial de nuestro contexto para conocer la realidad y conocer el texto sobre el Jesús de Galilea. Dicho con total sencillez, sin ellos difícilmente se comprenderán textos como el evangelio de Jesús, al menos con la profundidad que les es propia. De ahí que, en lo personal, me causa desasosiego la indeferencia hacia los mártires en no pocas teologías.

$* * *$

Para terminar, tres reflexiones obvias.

La primera es que en ese artículo se pudieran haber analizado muchas otras cosas sobre el Jesús de Galilea. Alguna de ellas, absolutamente central, como la relación de Jesús con el Padre, y la realidad última de Jesús - digamos metafísica-, lo que abordé en los dos libros citados al principio. Otras son de gran actualidad y deben ser abordadas: Jesús y las religiones, la mujer y su situación en la creación y en la Iglesia, una salvación que integre los logros de la razón en la tarea de la liberación, la Iglesia como resultado del movimiento de Jesús, su actitud real ante el servicio y el poder, la libertad y el servilismo... Espero, sin embargo, que lo dicho baste para mostrar la importancia del contexto salvadoreño y de los mártires en la reflexión cristológica. 
La segunda es si y cómo historizar hoy lo que aprendimos en un contexto de irrupción y de martirios que fue epocal, difícilmente repetible, aunque no totalmente distinto. Esperamos que lo dicho ayude a mantener, de alguna forma, la comprensión de la "irrupción original" y a discernir nuevas "irrupciones", que serán, en definitiva, los signos de los tiempos más verdaderos. Y que ayude a mantener a los mártires. Y si la tarea parece casi imposible para la teología, piénsese que ésa, y no otra, es la tarea fundamental de una teología cristiana: mantener viva la "irrupción del mártir Jesús".

La tercera es la más evidente. He dado mi opinión personal sobre Jesús y algunos elementos de su persona. Y más que en muchos contenidos me he fijado en lo que se suele llamar método. En mis textos no he seguido un método a prio$r i$, para lo que no me creo capacitado, ni en lo que, sinceramente, tampoco pongo excesiva confianza. He repensado simplemente el camino que he recorrido en El Salvador. Ellacuría, sin duda, lo hubiera dicho de otra forma. Y lo mismo harían teólogos y teólogas de América Latina y de todo el Tercer Mundo. Pero quizás haya algo común a todos: tomar en serio el contexto del mundo de pobreza, pasar por una ruptura epistemológica, pensar al servicio de la liberación. Y desde El Salvador, tomar en serio a los mártires. 